\title{
Spiral Antenna with Hilbert Antenna for Body Worn Application
}

\author{
Muskan Bhatia, Akashdeep Chakraborty, PS Sharma, Brajlata Chauhan
}

\begin{abstract}
In the present scenario in the field of human health service and body worn application, the major concern is to detect the actual cause of the pain in human body. In this paper the design and proper shape of antenna for a particular body part like knee, elbow or any other joints are presented with the optimized characteristics and comparison between spiral and Hilbert antenna so that the proper parameters like temperature, lubrications or any damage can be analysis. And for security service, the concern is for small size and minimum loss. Now these antenna devices transmit the physiological data from the body for health purpose and for security purpose and desired information will be transmitted from the body to the peripheral device. These two antennas are designed at operating/resonant frequency of $500 \mathrm{MHz}$ with main objectives of minimum size, minimum error, less power consumption and proper shape of antenna to fit the body part after calculating the SAR value.
\end{abstract}

Keywords: Advance design system (ADS), Hilbert antenna, implantable-health-security antenna, spiral antenna,

\section{INTRODUCTION}

During the medical history, the doctor asks the patient how long symptoms have been present and what are the problems you are having using your knee or any other joints. In addition, the doctor asks about any injury, condition or health problem that might be causing such problems. But the now after so many innovations in the field of medical these things may be asked by the doctors but to get a proper situation of the joint an implantable antenna can be used with proper size and shape [6]. The antenna implanted can transmit the information the CRO outside which contain the information of joint's temperature, lubricate generation, noise of the two bones rubbing, and any damages made to the joints in case of injury. As the security is also the one of the leading worry of the humans so these antenna can be implanted near or over the joints because the desired as the shape of the antenna are perfectly matches the joints shape and hence cannot be detected by the other person.

Revised Manuscript Received on July 02, 2020.

* Correspondence Author

Muskan Bhatia*, Dept. Of EECE DIT University,Dehradun, UK, India. E-mail: muskan.1902bhatia@gmail.com

Akashdeep Chakraborty, Dept. Of EECE DIT University,Dehradun, UK, India. E-mail: a.d.chaks@gmail.com

PS Sharma, Dept. Of EECE DIT University,Dehradun, UK, India. Email: pss@dituniversity.edu.in

Brajlata Chauhan, Dept. Of EECE DIT University,Dehradun, UK, India. E-mail: braj.lata@rediffmail.com

(C) The Authors. Published by Blue Eyes Intelligence Engineering and Sciences Publication (BEIESP). This is an open access article under the CC BY-NC-ND license (http://creativecommons.org/licenses/by-nc-nd/4.0/)
These antenna also transmit the information with less error and less power consumption with the maximum gain [5] thus can be very beneficially for the security as well as health purpose. A CPW antenna discussed for W LAN and ISM application using cross tuning stub on FR-4 substrate [7]. A textile and wearable antennas survey publish in research that proposed different fabrics and an unconventional antenna which is to be a part of clothing and body [11]. A flexible antenna article presents with poly dimethylsiloxane based on body worn applications. In order to reduce the specific absorption rate (SAR) [12]. A horizontal slot and a stack patch is incorporate to produce wide band MSA at $2.4 \mathrm{GHz}$ [13]. The low dielectric constant of substrate is used; patch is design on thin glass fiber supported by low density foam over ground plane.

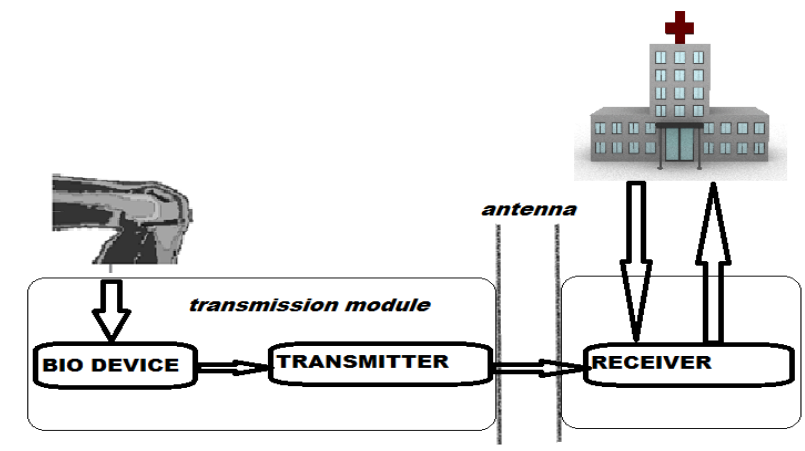

Fig 1: Architecture diagram

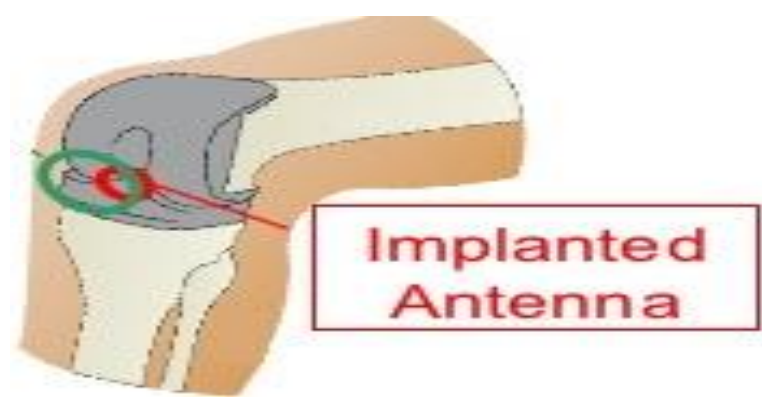

Fig 2: Implanted antenna in knee

The objectives of this design are

- Minimum size, Light weight

- $\quad$ Proper shape to fit the body part

- Less harmful radiation,

- Minimum error with focus beam

- $\quad$ More life, High antenna gain

- Less power consumption

- May fabricated on cloths also

- Study of flexible substrate

- $\quad$ Study of Body worn antennas

Published By:

Blue Eyes Intelligence Engineering

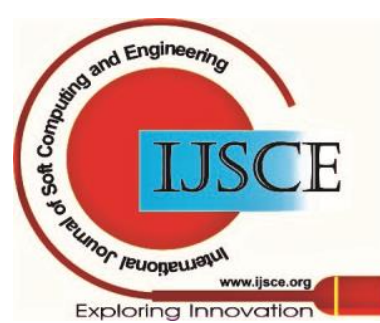




\section{Spiral Antenna with Hilbert Antenna for Body Worn Application}

Hilbert antenna is the fractal antenna which is a broken curve self-symmetrically aligned in a model.

It take the length then self-aligned its size and shape [1]. It is usually iterated/repeated by " $n$ " which is the order of the antenna or in simple which is the number of turns given to for body worn application. The both proposed antenna will be flexible because of its structure. That can be implemented on cloth, or any curvature surface.

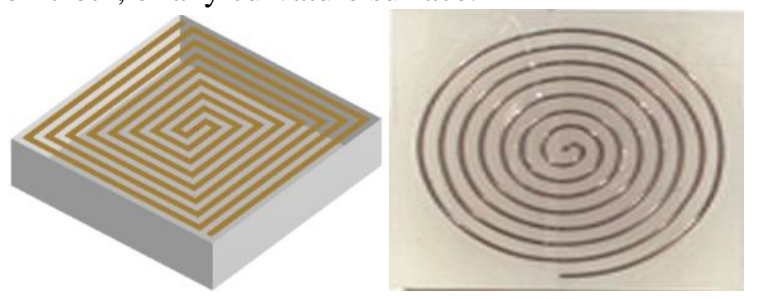

Fig 3: Hilbert antenna and Spiral antenna
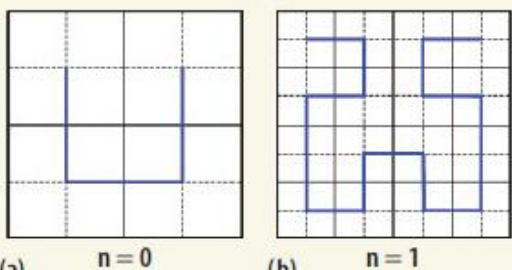

(b)

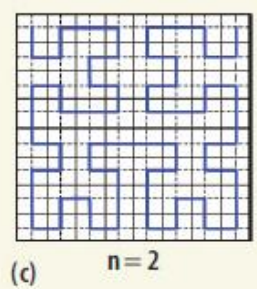

Fig 4: Hilbert curves of order (a) zero, (b) one, and (c) two

Spiral antenna is a 2 dimensional circular antenna. It is continuous concentric antenna with the specific radius to get the proper matching. The number of the turns of the concentric circles are given by " $n$ "[7]. Its beam is concentrated at the center of the circle of desired radius of antenna.

\section{METHODOLOGY, SCHEMATIC AND LAYOUT}

\section{A. Method of Moments}

In methods of moments, the dielectric currents flowing over the patch metallization and the ground plate are solved by rich mound reaction method. The integral equations thus obtained are solved using the boundary condition and the method of moments. Now using expansion function, for surface currents, the integral equation are converted to algebraic equations.

$$
u ? ?_{n=1}^{N} u_{n}=?_{n=1}^{N} I_{n} b_{n}, \mathrm{~N}=1,2,3 \ldots
$$

Here, $b_{n}$ is the expansion function, $I_{n}$ is the unknown complex coefficients of the complex, $\mathrm{N}$ is the total number of expansion function.

Now these obtained equations are then solved for the unknown's coefficients using method of moments which is analytically simple and versatile method but need large computation. Design and Schematic of the antennas are done in advance design system ADS software. The operation frequency is $5 \mathrm{MHz}$. Dimensions of the substrate are-

- $\quad$ permeability of the substrate $(\varepsilon)=3.1$

- $\quad$ Thickness $(\mathrm{T})=0.017$

- $\quad$ Conductance $(\mathrm{C})=4.70 \mathrm{E}+7$ the antenna. Hilbert antenna is shown in Fig-3. At low frequency back radiation will be less which is less harmful

- $\quad$ Loss tangent $($ Tan D) $=0.0025$

- Height of the substrate $(\mathrm{H})=2.75$

\section{B. Schematic}

\section{a. Hilbert Antenna}

Hilbert curve can pack the longer length in a given area because of space filling properties and self-similarity which allow many iteration hence it is a broad band width. It is widely used in air to air wireless application design[2].

$$
f_{k} ? f_{d}\left[1-\exp \left(\frac{n-1}{n}\right) \ln \frac{d}{d}\right]
$$

The multiply square curves are the main reasons to make this antenna workable at multiply frequency because of which perimeter increases but electrical length decrease. Hilbert antenna and spiral antenna are designed with advance design system with following specifications given in table 1 and table 2 respectively.

Table 1. Specification of Hilbert antenna

\begin{tabular}{|l|l|}
\hline Resistance & $140.65 \mathrm{ohm}$ \\
\hline Capacitance & $3.2 \mathrm{pF}$ \\
\hline No. of turns & 7 \\
\hline Total length & $58.9 \mathrm{~mm}$ \\
\hline Width & $3.2 \mathrm{~mm}$ \\
\hline Spacing & $1 \mathrm{~mm}$ \\
\hline
\end{tabular}

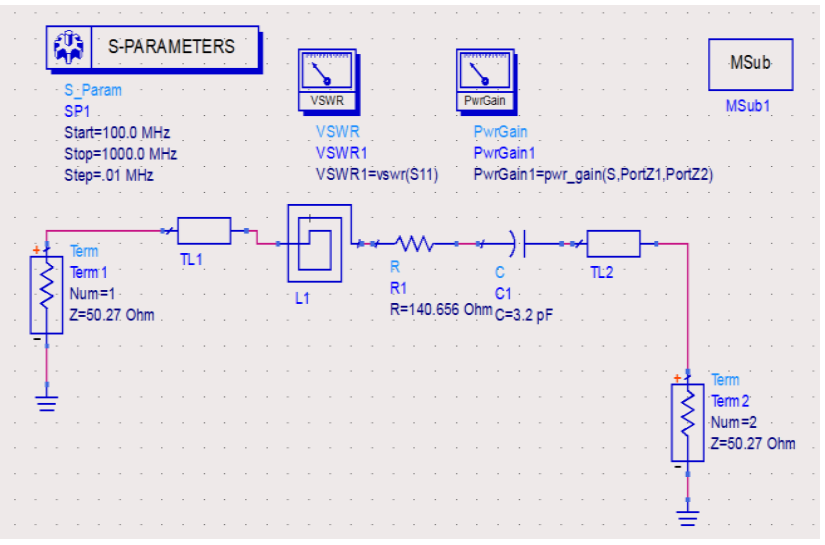

Fig5: Schematic of Hilbert antenna

Schematic is achieved by the Schematic window in advance design system software with the specification taken from table 1. Substrate used is the above antennas have the above properties and specification discussed above.

b. Spiral Antenna

Spiral antenna is circularly polarized and its radiation pattern has maximum radiation perpendicular to the plane of spiral [8]. When it is placed inside the muscle tissue, it must be protected from the human body tissue which has a dielectric of 42.8 thus a protection is required which is called superstrate layer [9].

$r=R_{0} e^{a b}$

It is usually used in defense industry for sensing application and also in GPS, because of its small size.

Published By:

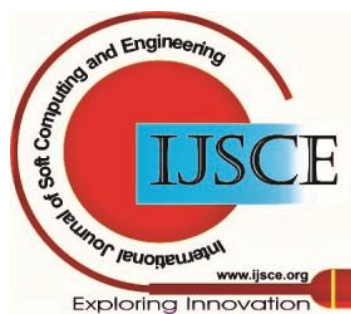
and Sciences Publication

(C) Copyright: All rights reserved. 
Table 2. Specification of spiral antenna

\begin{tabular}{|c|c|}
\hline Resistance & $125.56 \mathrm{ohm}$ \\
\hline Capacitance & $2.3 \mathrm{pF}$ \\
\hline No. of turns & 7 \\
\hline Radius & $6.5 \mathrm{~mm}$ \\
\hline Width & $3.2 \mathrm{~mm}$ \\
\hline Spacing & $1 \mathrm{~mm}$ \\
\hline
\end{tabular}

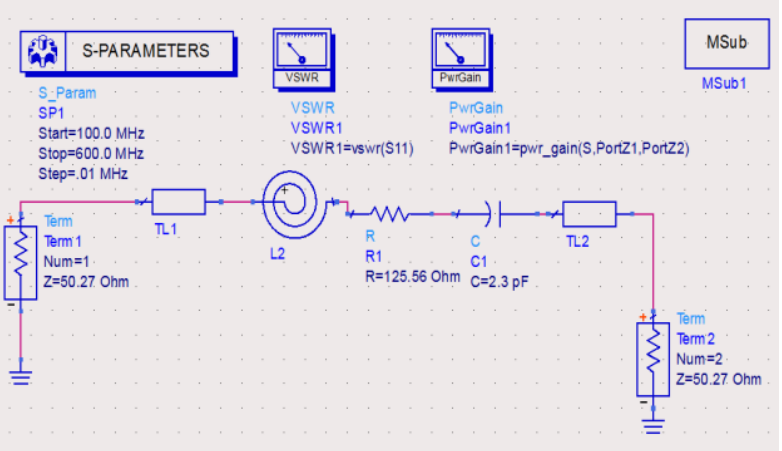

Fig 6: Schematic of Spiral antenna

The substrate parameters are same as discussed above. The VSWR meter, Power Gain, S-parameter have the same meaning discussed above. After the MSIND on both the ends micro strip line is used with the same width of 2.75 $\mathrm{mm}$ and with the same substrate .Resistance and capacitance are connected in series so as to provide the matching to the antenna. Both the side of the micro strip line is terminated by the terminator of impedance of $50.27 \mathrm{ohm}$.

\section{Layout}

In Both cases, the iteration is taken as " $n$ " which is equal to 7.Layout is obtained with the two ports and the two transmission strip lines are connected with the ports of the same width as the antenna.

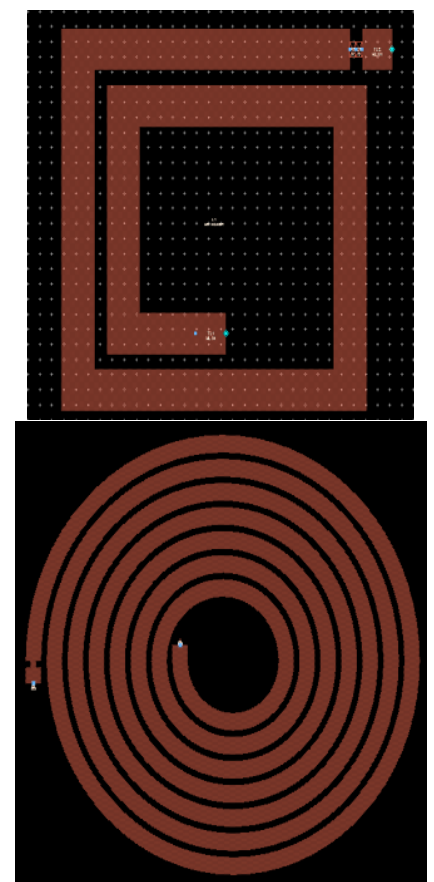

Fig7: Layout of Hilbert and Spiral antenna

\section{SIMULATION AND RESULT ANALYSIS}

\section{A. Simulation analysis of Hilbert antenna}

Simulation is achieved in the simulation window in ADS.Sparameter. The plot between s-parameter and frequency, VSWR and frequency and power gain is plotted in the simulation window.

From the above plot it can be seen that the losses are less at the operating frequency of $500 \mathrm{MHz}$ as the $\mathrm{S}_{11}$ plot is below $-10 \mathrm{db}$ and is at $-14.45 \mathrm{db}$. Bandwidth can be measured by the $S_{11}$ plot the region below $-10 \mathrm{db}$. The magnitude of the standing wave can be measured in terms of standing wave ratio.

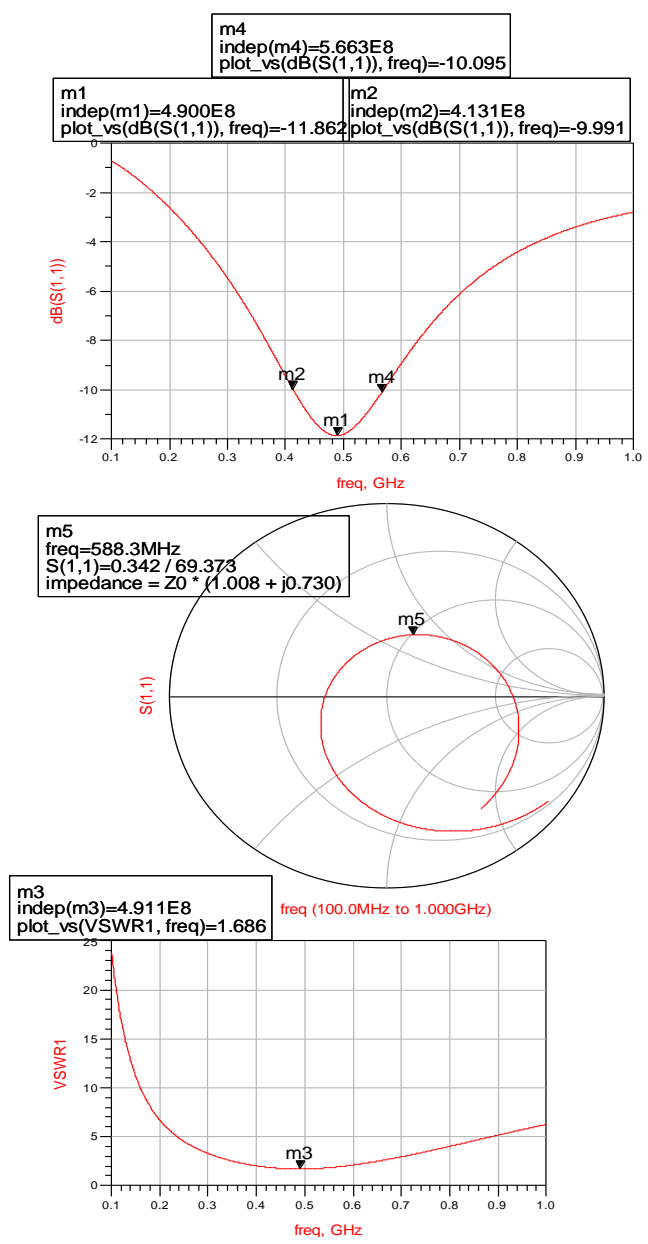

Fig 8: Simulation result for return losses, Impedance and VSWR of Hilbert antenna

. The VSWR at the operating frequency of $500 \mathrm{MHz}$ is 1.68.The power-gain of the antenna at the frequency of 500 $\mathrm{MHz}$ is -4.508 .

\section{B. Simulation analysis of Spiral antenna}

In the simulated plot for $S_{11}$ is $-42.33 d b a t$ the center frequency of $500 \mathrm{MHz}$ which is less than the Hilbert antenna and also offering a $2^{\text {nd }}$ resonance at $356.6 \mathrm{MHz}$. This implies that the losses are too small and can also be used at 356.6 MHz. The impedance of antenna is $\mathrm{Z}_{0} \times(1.044$ + j0.013) shown on the smith chart at center $500 \mathrm{MHz}$. The VSWR graph showing value is approximately 1.05 .

Published By:

Blue Eyes Intelligence Engineering

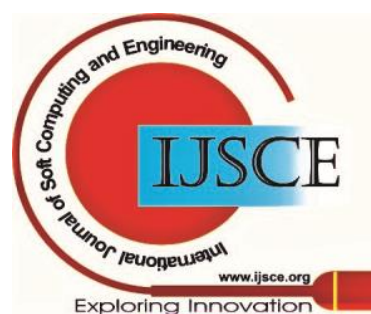




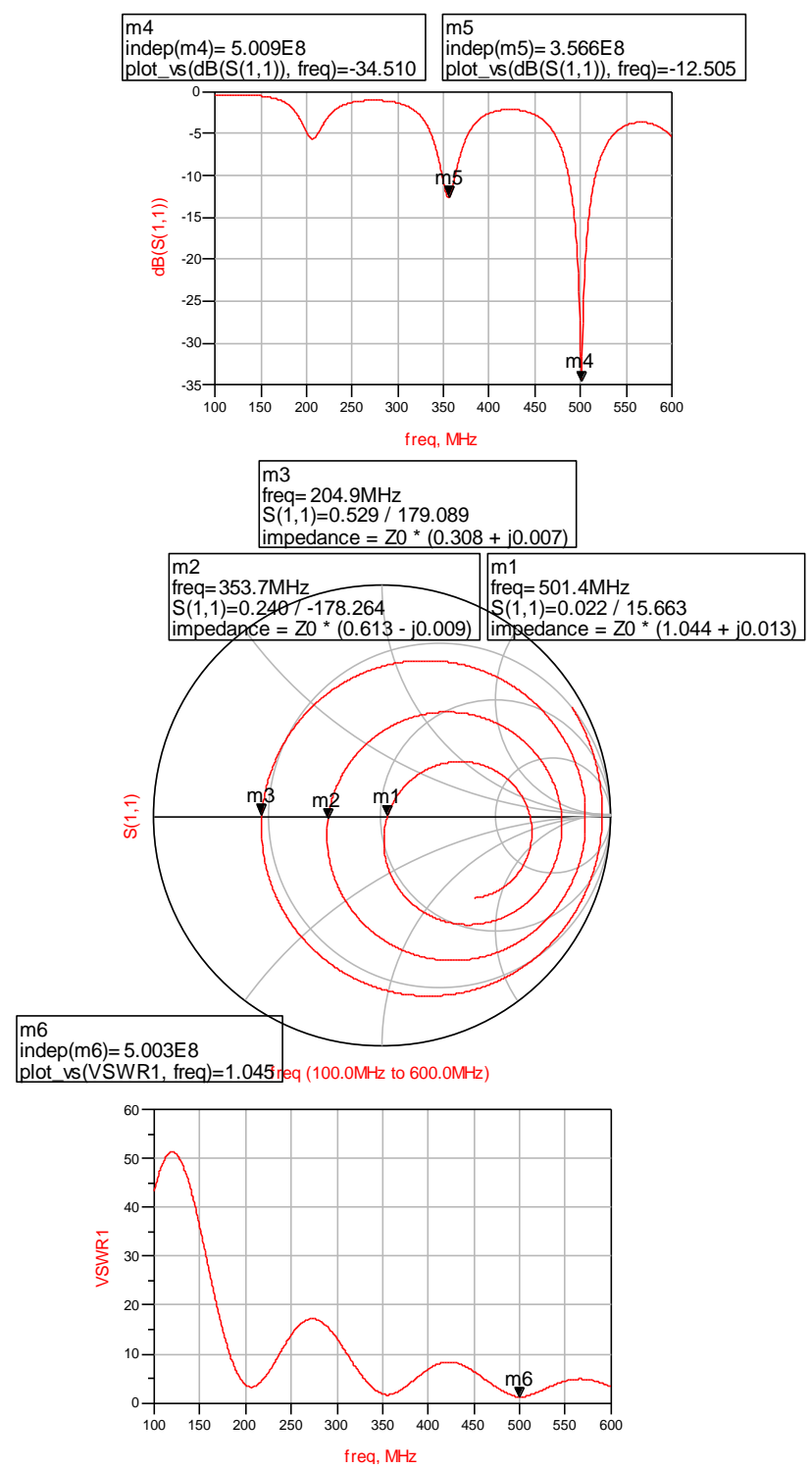

Fig 9: Simulation result for return losses, Impedance and VSWR of Spiral antenna

\section{COMPARISON OF HILBERT AND SPIRAL ANTENNA}

Table: 3 Comparison of both the antennas summarized in the form of table, in which spiral antenna producing better performance of transmission line parameters.

\begin{tabular}{|l|l|l|}
\hline Parameter & Hilbert Antenna & Spiral Antenna \\
\hline Shape & square & circle \\
\hline Area occupied & $334.89 \mathrm{~mm}^{2}$ & $132.73 \mathrm{~mm}^{2}$ \\
\hline Resistance & $140.65 \mathrm{ohm}$ & $125.56 \mathrm{ohm}$ \\
\hline S $_{11}$ (negative) & $11.86 \mathrm{db}$. & $34.51 \mathrm{db}$. \\
\hline Capacitance & $3.2 \mathrm{pF}$ & $2.3 \mathrm{pF}$ \\
\hline Dimension & $58.9 \mathrm{~mm}$ & $6.51 \mathrm{~mm}$ \\
\hline Bandwidth & 0.71 & 0.15 \\
\hline VSWR & 1.68 & 1.05 \\
\hline
\end{tabular}

\section{RADIATION PATTERN AND MOMENTUM REALIZATION}

Both the points mentioned above are optimized in ADS for spiral antenna as from the comparison it is seen more advantageous.

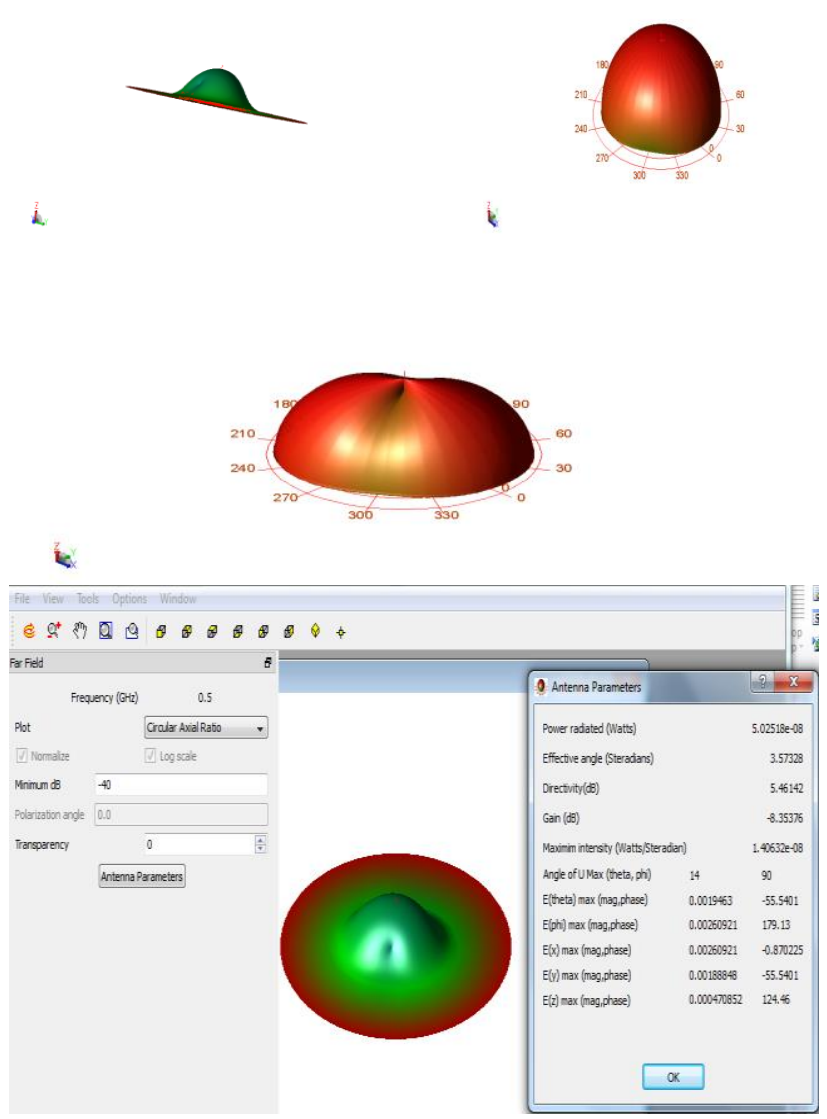

Fig: 10 Radiation pattern

The proposed antenna design producing the directivity of $5.4 \mathrm{~dB}$ and the reflection coefficients $S_{11}$ is $-42.33 \mathrm{db}$ at the center frequency of $500 \mathrm{MHz}$ and $S_{11}$ is $-12.38 \mathrm{db}$ for $2^{\text {nd }}$ resonance at $356.6 \mathrm{MHz}$.

\section{CONCLUSION}

Design, characterization, simulation are done successfully in advance design system (ADS). Substrate taken in both antenna are same and also the iteration " $n$ " is same so as to proper compare the antennas. Hence it is seen that the area is less required for spiral antenna and is more easy to implant for health purpose But the Hilbert antenna on the other hand, it has the large bandwidth as compares to spiral antenna and easy to hide for security purpose and the $S_{11}$ parameter is less in spiral antenna implies that the error in the transmission is less in spiral antenna which is also advantageous both in security and in health purpose. On the other hand, Hilbert antenna can be used only in case when we require comparatively large bandwidth with gain of 5.4 $\mathrm{dB}$. Furthermore, To calculate the SAR value for the body worn antenna. we can export the file to CST and HFSS software and find the specific absorption rate which is suitable for body tissue.
Published By:

Blue Eyes Intelligence Engineering and Sciences Publication

(C) Copyright: All rights reserved.

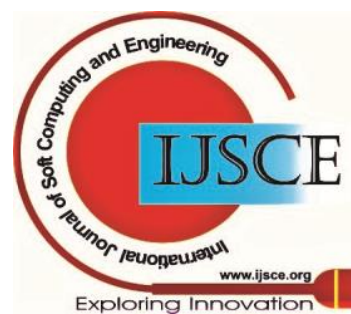




\section{REFERENCES}

1. Azaro, Renzo and Viani, Federico and Lizzi, Leonardo and Zeni, Edoardo and Massa, Andrea (2011) A Monopolar Quad-Band Antenna based on a Hilbert Self-Affine Pre-Fractal Geometry.

2. K. J. Vinoy, K. A. Jose, V. K. Varadan, and V. V. Varadan, "Hilbert curve fractal antenna: A small resonant antenna for VHF/UHF applications" Microwave Opt. Tech. Letter., vol. 29, no. 4, pp.215 2192001

3. S. R. Best, "A comparison of the performance properties of the Hilbert curve fractal and meander line monopole antennas", Microwave Opt. Tech. Lett., vol. 35, no. 4, pp.258 -262 2002

4. E. A. Parker and A. N. A. El Sheikh, "Convoluted array elements and reduced size unit cells for frequency-selective surfaces", Proc. Inst. Elect. Eng. Part H: Microwaves, Antennas, and Propagation, vol. 138, pp.19 -22 1991

5. J.-Y. Sze and K.-L. Wong "Bandwidth enhancement of a microstripline-fed printed wide-slot antenna", IEEE Trans. Antennas Propag., vol. 49, pp.1020-102 2001

6. R. Nilavalan and I. J. Craddock "Wideband microstrip patch antenna design for breast cancer detection", IET Microwave. Propag., vol. 1, no. 2, pp.277 -281 2007

7. Sandeep $\mathrm{Kr}$ Singh1, Rajendra Singh2*, Himanshu Parashar3, Vepakomma Kavya "Design of CPW-Fed Circularly-Polarized Antenna with Cross Tuning Stub for WLAN/ISM Band Application” International Journal of Computer Sciences and Engineering, volume 6, issue 32018

8. Y. S. Yeh and K. K. Mei "Theory of Conical Equiangular-Spiral Antennas Part II - Current Distributions and Input Impedances", IEEE Trans. on Antennas and Propagation, vol. AP16, pp.14 -21 1968

9. H. Nakano , M. Ikeda , K. Hitosugi , J. Yamauchi and K. Hirose "A spiral antenna backed by an electromagnetic band-gap material", Proc. Antennas Propagation Soc. Int. Symp., vol. 4, pp.482 -485 2003

10. T. H. Liu , W. X. Zhang, M. Zhang and K. F. Tsang "Low profile spiral antenna with PBG substrate", Electron. Lett., vol. 36, pp.779 7802000.

11. Ankita Priya and Chauhan Brajlata "A Review of Textile and Cloth Fabric Wearable Antennas" International Journal of Computer Applications, USA Vol. No. 116, Issue 17, pp.1-5, 2015.

12. Yaya Zhang, Jiyong Hu "Dielectric constants of sewed multilayer fabric for wearable e-textiles" Journal of Industrial textiles, DOI 10.1177/1528083720915542 April 2020.

13. Shubham Chouhan, Rajdeep Shrivastava, "Design and Analysis of Different Types of Modern Methods Using Line Feed of Microstrip Antenna Using CST Software," International Journal of Computer Sciences and Engineering, Vol.7, Issue.4, pp.594-603, 2019.

14. Brajlata Chauhan, Vijay sandip and S. C. Gupta "Slow Wave-IDC Loaded High Bandwidth Microstrip Antenna Operates For Multi Band Applications" International Journal of Computer science and information security ,IJCSIS Pittsburgh, USA, Vol.14, No. 4, pp.120125, 2016.

\section{AUTHORS PROFILE}

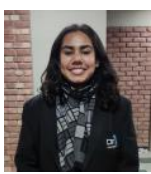

Miss Muskan Bhatia perusing her bachelors of Engineering in Electronics and Communication Engineering from DIT University Dehradun, India. I had worked as a trainee at BSNL, Haridwar, Uttrakhand, India. Currently the member of Institution of Electronics and Telecommunication Engineers (IETE).

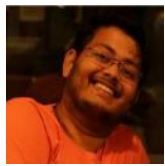

Mr. Akashdeep Chakraborty perusing bachelor of Engineering in Electronics and Communication Engineering from DIT University Dehradun, India. I had worked as an intern in BHEL Electronics division, Bangalore, India. I am also the member of Institute of Electrical and Electronics Engineers(IEEE).

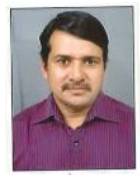

Mr. P. S. Sharma working as Assistant Professor in DIT University, Dehradun Since 2006. Received master's degree from Motilal Nehru National Institute of Technology (formerly MNREC). His area of interest is fiber-optics communication, Wireless Communication and Digital
Systems. Published research papers in reputed SCI Journals and National \& International Conferences. Member of the Institute of Electrical and Electronics Engineers (IEEE), ACM, Computer Society of India (Life Membership), Institution of Engineer (India). Till now, he has guided 28 M.Tech dissertations.

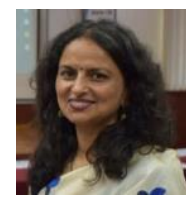

Dr.Brajlata Chauhan received her Ph.D in the field of Microstrip Conformal Antenna and M.Tech in Digital communication from Uttrakhand Technical University Dehradun UK India in 2017 \& 2010. She is commissioned in 2019 as Lieutenant in NCC . She is working as an Assistant Professor in the Department of EECE at DIT Univ. Dehradun, India. She has published more than 30 research papers in the field of MW \& Antenna in international Journals/conferences and guided $4 \mathrm{M}$.Tech students. She is member of IETE, IEEE,ISTE and having experience of mor

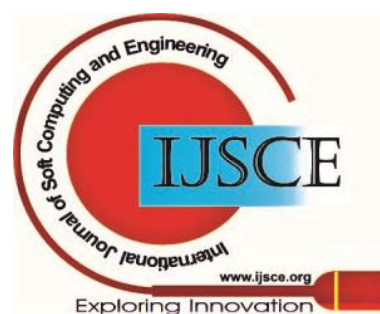

